\title{
El debate marxista sobre la crisis económica actual \\ Financiarización: ¿Causa 0 \\ consecuencia de la crisis capitalista?
}

BEATRIZ EsCobAR

Departamento de Economía, Universidad Centroamericana "José Simeón Cañas"

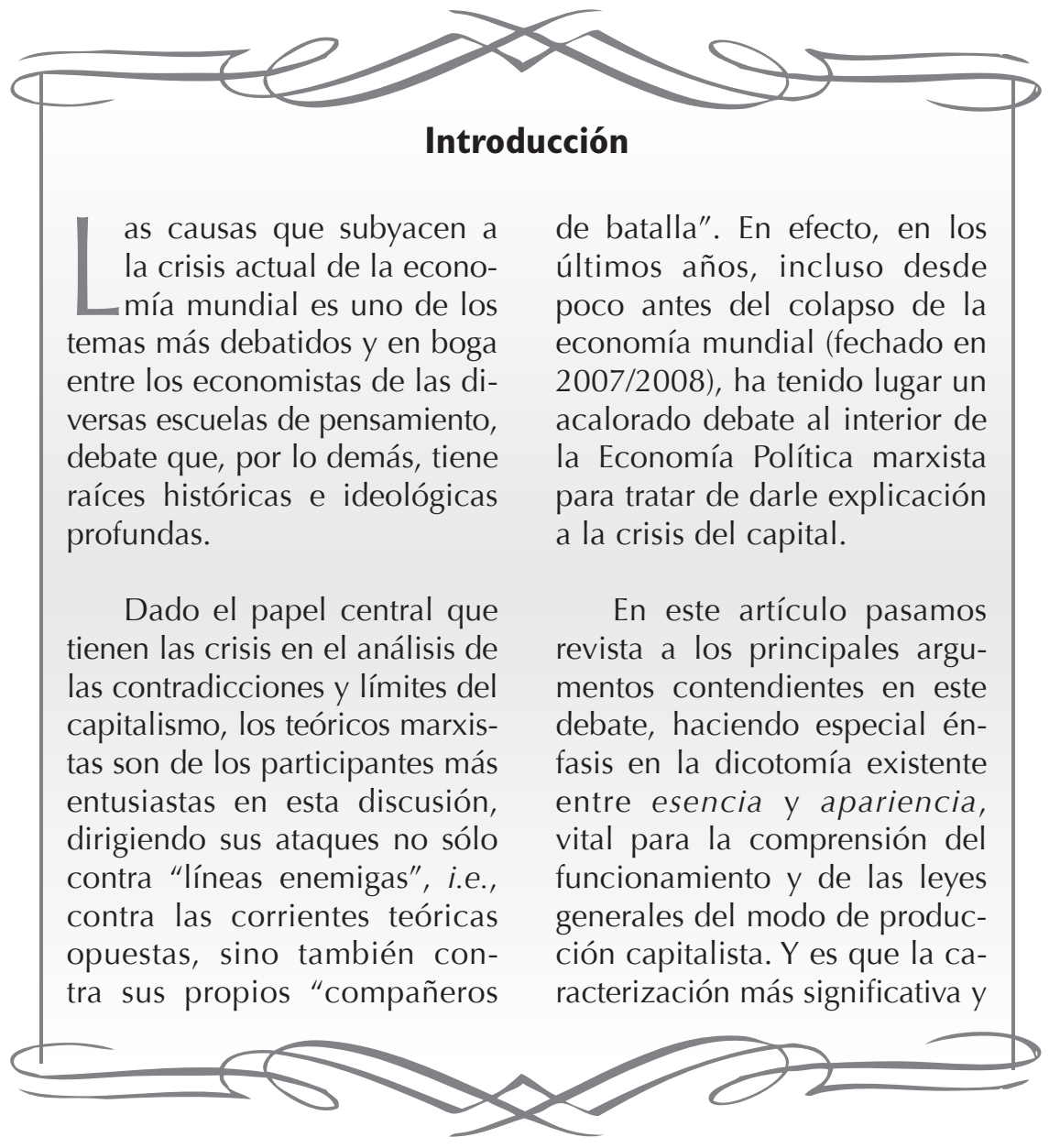


de amplia aceptación sobre la crisis económica, la denominada financiarización, adolece justamente de esa confusión entre lo que parece y lo que es, entre causa y efecto. Tal caracterización negaría incluso la Ley de la Tendencia Decreciente de la Tasa de Ganancia (LTDTG), comprendida y articulada de forma sistemática y coherente por primera vez por Marx, y considerada por él como "la ley más importante de la Economía Política moderna, y la más esencial para comprender sus relaciones complejas" (Marx 1973 [1857-58], p. 752. Traducido del Inglés). Así, para estos teóricos, la actual crisis no sería una crisis à la Marx, es decir, una crisis normal, esperada, del capitalismo, sino más bien una crisis de algunas de sus particularidades, de su modalidad actual específica, el neoliberalismo. De hecho, dichas teorías no parecerían tener como base las leyes propias del régimen capitalista de producción, sino una especie de "armonicismo" à la Say, tan criticado por Marx en su momento. La "inadecuación" de estas teorías para explicar la crisis no consiste, en nuestra opinión, en la inexistencia de los fenómenos que describen, presentes sin duda en la realidad, sino en que ubican dichos fenómenos como causas cuando en realidad son consecuencias, enturbiando así la comprensión de este modo histórico de producción. Causa y efecto se presentan pues de forma difusa y, en el mejor de los casos, confusa, haciendo obvia la ya men- cionada dicotomía entre esencia y apariencia.

El significado preciso del término financiarización es también muy debatido. Cada autor incorpora o excluye diferentes elementos de esta categoría. A grandes rasgos, sin embargo, puede ser entendido como el auge de los movimientos financieros y crediticios, especulativos y de formación de capital ficticio que, de acuerdo a algunos autores, está asociado con la desregulación adjudicada principalmente al neoliberalismo y, en el caso de Europa, asociado además con la Unión Económica y Monetaria (UEM), el euro, y su conformación. Este es el fenómeno central en torno al cual se ubican las distintas explicaciones comentadas a continuación.

Si bien encontramos al interior de la corriente marxista la posición que considera que tales teorías fenoménicas son políticamente "inocuas" (Katz 2010), es decir que carecen de consecuencias directas sobre la acción de los movimientos sociales y políticos, ${ }^{1}$ nuestra opinión es completamente distinta. Creemos que sin una explicación de la crisis que sea general y capaz de develar el verdadero rostro (de explotación, contradicciones y límites) del régimen capitalista de producción, las consecuencias, de cara a la acción social transformadora, de cara al "¿qué hacer?", pueden ser profundamente perjudiciales. He aquí la importancia crucial de este debate. 
O como lo plantea Palley (2012, sin número de página. Traducido del Inglés), "el debate es crítico porque cómo expliquemos la crisis influirá sobre lo que haremos [para enfrentarla]".

\section{El Debate}

Lo que aquí se presenta no pretende ser una revisión exhaustiva del debate en cuestión, sino más bien una guía que contribuya a ubicar e identificar las distintas teorías (y sus representantes) que participan en este tan importante "concurso literario", uno más entre los muchos en que los teóricos marxistas se han embarcado hasta la fecha.

Se observan dos variantes fundamentales en las teorías afiliadas a la financiarización: las que la consideran como la causa de la crisis, y las que la consideran una consecuencia de la misma.

\section{(a) Financiarización como causa}

En este grupo encontramos autores como Gérard Duménil, Dominique Lévy y, hasta cierto punto, en tanto posee algunas discrepancias, Michel Husson, para quienes la crisis actual es una crisis financiera en la que se expresaría, en realidad, una crisis de la modalidad particular del capitalismo de las últimas décadas: el neoliberalismo. Es, por tanto, una crisis de la modalidad actual específica del capitalismo, y no una crisis normal de este modo de producción. En otras palabras, no se trataría, como ya se sugirió, de una crisis provocada por la caída de la tasa de ganancia, de una pérdida de rentabilidad que afectaría a la tasa de acumulación del capital, sino de una crisis de las características específicas del neoliberalismo. ${ }^{2}$ Aunque, como estos autores señalan, que el neoliberalismo esté en crisis no significa que no vaya a sobrevivirla (Duménil y Lévy 2011)

Brevemente, la narrativa de estos autores es la siguiente: durante los años 70, el capitalismo experimentó una de sus crisis estructurales habituales, manifestada en la así llamada crisis de los precios del petróleo y crisis de la deuda de América Latina (i.e. la "década perdida"). En este caso, la tasa de ganancia de las empresas productivas en efecto habría caído. La respuesta a dicha caída habrían sido las medidas neoliberales: privatizaciones, flexibilización laboral, liberalización comercial, etc. ${ }^{3}$ Tal modalidad particular del capitalismo, que implicaba en última instancia una mayor expropiación y explotación de la clase trabajadora (i.e., incremento de la tasa de plusvalía), habría logrado recuperar la tasa de ganancia gracias justamente a ese ataque a las condiciones laborales que habría puesto fin a la crisis estructural. Pero habría logrado algo más: el resurgimiento de una 
hegemonía financiera, una fracción poderosa de la clase capitalista que, como fruto de la desregulación, se habría convertido en la dominante. $Y$ se habla de "resurgimiento" porque tal fracción habría tenido ya, antes de la Gran Depresión de 1929, y antes de todos los "controles" que se le impusiera con los acuerdos de Bretton Woods, un primer período hegemónico que habría conducido precisamente a la Gran Depresión. ${ }^{4}$

De modo que, según estos autores, la tasa de beneficio experimentó una recuperación significativa durante los años 80 , pero (y este es un "pero" importante), la tasa de acumulación de capital o tasa de inversión productiva no habría reflejado la trayectoria de la tasa de ganancia. En otras palabras, la recuperación de la tasa de ganancia no habría sido traducida en una recuperación de la tasa de inversión productiva, que continuaría deprimida, generándose así una brecha entre ambas. ¿La explicación de esta brecha? La financiarización, vale decir, la expresión de las tendencias neoliberales: los beneficios generados se habrían invertido en actividades financieras, esto es, actividades improductivas, en detrimento del capital productivo. Las finanzas estarían así drenando el capital necesario para inversión (Husson 2009b). ${ }^{5}$ Tal cosa habría ocasionado un desequilibrio, una desproporción entre capital ficticio y actividades productivas, desbalance que, adicio- nalmente, se vería alimentado por una insuficiente demanda agregada (teorías del "underconsumption" o del "consumo insuficiente" ${ }^{6}$ ) como resultado del ataque contra los salarios reales (i.e., problemas de distribución de ingreso) que lideraran las políticas neoliberales.

Así, la esfera financiera, con suficiente independencia y autonomía, estaría ocasionando problemas a la esfera productiva, explicación que se apartaría visiblemente de la teoría laboral del valor de Marx, ${ }^{7}$ y que postularía, además, un falso conflicto entre capital productivo ("bueno") y capital financiero ("malo"). Dicho conflicto, heredero de un fuerte espíritu keynesiano y vebleniano, encubriría el carácter del capital como un todo (y de los intereses que, como clase, los capitalistas comparten a nivel de capital-en-general, muy a pasear de su interacción conflictiva a nivel de muchos-capitales), así como el problema del capitalismo como organización social de la producción. ${ }^{8}$ Esta crisis del neoliberalismo sería una crisis provocada por la hegemonía del capital financiero, y específicamente, una crisis de la hegemonía de Estados Unidos, con lo que, como señala Mateo Tomé (2011), la crisis quedaría adicionalmente relacionada con las teorías sobre el imperialismo. ${ }^{9}$

En aras de la rigurosidad, es necesario en este punto separar -aunque sea de manera formal- 
la postura de Husson de la de Duménil y Lévy. Husson correctamente señala, contrario a lo que su análisis general parece indicar, ${ }^{10}$ que la esfera financiera no es autó- noma. La principal función de las finanzas es, de hecho, borrar lo más posible las fronteras y límites de las áreas de valorización del capital:

La función de las finanzas es la de endurecer las leyes de la competencia a través de hacer fluidos los desplazamientos del capital... La principal característica del capitalismo contemporáneo no reside entonces en la oposición entre capital financiero y capital industrial, sino en la hipercompetencia entre capitales a la que conduce la financiarización (Husson 2008a. Traducido del Inglés).

Si bien Husson (2008b) acepta que la relación entre capital financiero y capital productivo ha sido profundamente modificada en los últimos años, tal modificación no eliminaría la interrelación irresoluble que existe entre ambos. De ahí que no deba tomarse la visión "financiarista" del capitalismo contemporáneo que ve una tendencia autónoma de la financiarización, plagando y entorpeciendo el funcionamiento normal del capital industrial "bueno":

Sería artificial separar el rol de las finanzas de la lucha de clases sobre el valor producido. Debemos articular el análisis del fenómeno correctamente: cuando la tasa de ganancia aumenta gracias a la disminución de los salarios, sin crearse las condiciones para una acumulación rentable, las finanzas toman un rol funcional en la reproducción a través de proporcionar una válvula de escape alternativa a la demanda económica de los asalariados ${ }^{11}$ ... la financiarización no es un factor autónomo, sino el complemento lógico de la reducción salarial y de la escasez de oportunidades de inversión suficientemente rentables. (Husson 2008b. Traducido del Inglés. Énfasis añadido)

Es más, Husson (2008c, 2010) dirá que la financiarización es un resultado, una respuesta a contradicciones de la economía real de larga data, por lo que cada crisis financiera (como la actual) debe ser interpretada como un llamado de orden de la teoría del valor. Y con esto último, este autor parecería estar a medio camino entre financiarzación como causa y financiarización como consecuencia. 
Sin embargo, es interesante advertir que lo que Husson plantea es que una vez recuperada la tasa de ganancia después de la crisis de los años 70, gracias al ataque a las condiciones de la clase trabajadora, ese "capital recuperado" se ve, entre otras cosas, ${ }^{12}$ sin "alternativas de inversión", sin "condiciones para una acumulación rentable", condiciones que consisten, en el análisis final, en una mayor tasa de ganancia, viéndose forzado a invertir en actividades financieras y especulativas. Su explicación cae, de este modo, en una confusa tautología sin solución. Si con una tasa de ganancia "aumentada" el capital no dispone de alternativas rentables de inversión productiva, viéndose obligado a dirigirse a la esfera financiera, es porque entonces la tasa de ganancia no ha sido recuperada, o al menos no lo suficiente. La existencia de una relación inversa entre tasa de ganancia y actividad financiera sobre-estimulada estaría implicada, siendo la primera la causa última de la segunda. En general estos autores no se preguntan:

a. De dónde surgen las ganancias de las actividades financieras, dado que, como ellos mismos lo postulan, tales actividades son improductivas, i.e. no generan plusvalía.

b. El por qué de ese dramático auge en la actividad financiera, si es que la tasa de acumula- ción en efecto se comporta como lo describen, es decir, divorciada de la trayectoria de la tasa de ganancia. ${ }^{13}$ Dicho de forma distinta, ¿qué, más allá de las "políticas favorables" que mencionan, hace que se dé ese excesivo movimiento en las actividades financieras?

Si bien fundamental para el funcionamiento del capital, para su "fluidificación", como lo señala Husson (2008a), la esfera financiera no es autónoma ni independiente de la esfera productiva. Todo lo contrario, establece con ésta una relación dialéctica, una relación bidireccional, aunque en última instancia, y en similar espíritu que la relación que describe Marx entre estructura y superestructura, es la esfera productiva la dominante, en tanto la participación de la esfera financiera en las ganancias, así sean futuras, depende del desempeño de la actividad productiva $y$, en definitiva, del comportamiento de la tasa de ganancia. Una insuficiente tasa de rentabilidad en la esfera productiva puede desembocar en una huída de capitales hacia ámbitos más líquidos y de plazos de cobro más cortos, hacia ámbitos "más rentables" en ese momento específico, i.e., hacia actividades financieras cuyo auge, si bien es facilitado por políticas amigables, es provocado por una caída de la tasa de ganancia. Pero mientras la crisis no se hace pre- 
sente, con su carácter necesario y de limpieza, como Kliman (2010) reconoce (ver siguiente sección), ${ }^{14}$ el capital que devenga interés o capital financiero, sigue ejecutando con normalidad su función de lubricante del movimiento del capital global, incluso si, en este proceso, resulta más beneficiado que algunos capitales industriales particulares:

Este es también el período durante el cual el capital dinerario se enriquece a costa de interés industrial. En cuanto a la caída del capital puramente nominal, bonos del Estado, acciones, etc. -en la medida en que no conduce a la quiebra del Estado o de la misma empresa, o a la paralización total de la reproducción a través de socavar el crédito de los capitalistas industriales que mantener valores- sólo supone la transferencia de riqueza de un lado a otro y, en general, actúa favorablemente sobre la reproducción, ya que los advenedizos en cuyas manos las acciones o participaciones abaratadas caen, son en su mayoría más emprendedores que sus antiguos propietarios. (Marx 1968, p. 706. Traducido del Inglés. Énfasis nuestro.)

La implicación política fundamental que se desprende de las posturas de este grupo es que la crisis es algo evitable, algo que es posible controlar a través política económica, o mejor, a través de un cambio de la política aplicada. Así, una vez los equilibrios sean restablecidos, suprimiéndose las políticas desacertadas y dañinas del modelo neoliberal que cedieron demasiado espacio al sector financiero -cuyo "espíritu salvaje" ávido de ganancia "fácil y rápida", necesita de una correa más corta-, la economía funcionará, sino a la perfección, sí de una mejor manera. ${ }^{15}$ Esto deja al descubierto que no se trata de una teoría general capaz de explicar las crisis en el capitalismo, al ser éstas, en algunos casos -como el de la crisis actual-, meros eventos accidentales y no partes constitutivas de este régimen de producción.

\section{(b) Financiarización como consecuencia}

En una línea muy similar, pero al otro lado de la cadena causaefecto, se encuentra la escuela de la Monthly Review, revista académica internacional de larga trayectoria que, enfocada en los problemas de desequilibrio provocados por una insuficiente demanda -causada por el capital monopolista y salvada por el capital financiero- $y$ fiel a su tradición teórica del "consumo insuficiente", sitúa la explicación de la crisis en el contexto del capitalismo monopolista (imperialista), cosa que hace de su explicación una teoría unidireccional: 
[V]emos que la tendencia hacia la monopolización de las empresas, la cual genera una tendencia a la expansión de la ganancia, provoca un desequilibrio que conduce a un crecimiento por debajo del potencial, o a una tendencia hacia el estancamiento. Metodológicamente, y a diferencia de otras explicaciones de la financiarización, en su análisis [Sweezy] parte del proceso productivo para explicar la mencionada financiarización, específicamente para explicar el creciente excedente generado por estas macro-corporaciones, y que constituye la nueva ley del desarrollo capitalista, "la ley de los excedentes crecientes". Pero esta extraordinaria capacidad productiva se enfrenta con una demanda insuficiente. En ausencia de proyectos de inversión productiva que contemplen un buen retorno esperado, cuya causalidad está basada en la imposibilidad de vender los productos, el capital es dirigido hacia el sector financiero. Estos flujos de capital conducen a una tendencia ascendente en los precios de los activos financieros, activos que ofrecen retornos más altos que otros sectores, explicando así, endógenamente, la razón por la que burbujas especulativas surgen periódicamente (explosiones financieras). La financiarización sería entonces una consecuencia de los obstáculos al proceso de acumulación "real", sirviendo como elemento contrarrestante de la tendencia hacia el estancamiento, en ausencia del cual ésta sería aún mayor, dado su impacto favorable sobre la demanda agregada (Magdoff y Sweezy, 1987). (Mateo Tomé 2011, sin número de página. Traducido del inglés. Énfasis añadido)

Se indicaría así, y a raíz del capitalismo monopolista, una distribución del ingreso perjudicial para el trabajo, lo que redundaría, a su vez, en una insuficiente demanda agregada $y$, consecuentemente, en un insuficiente nivel de consumo. De nuevo tendríamos los desequilibrios señalados en la aproximación anterior, los referidos a los desequilibrios entre oferta y demanda (causados por una demanda deficiente), y entre capital productivo y capital financiero que, en este caso además, actuaria como paliativo frente al estancamiento. La solución sería entonces obvia: política económica, relacionada con incremento de salarios y medidas "antimonopolio". Así, la crisis, de acuerdo a esta postura, podría ser controlada.

En la tesis de la financiarización como consecuencia, encontramos además la posición de la SOAS (School of Oriental and African 
Studies -Escuela de Estudios Orientales y Africanos, Universidad de Londres) y de su representante, Costas Lapavitsas, que ensaya una explicación enfocada al caso de la Unión Europea (UE), región en la cual la crisis se ha manifestado de forma especialmente trágica.

De acuerdo con los autores de esta escuela (Lapavitsas et ál. 2011, p. 132), la crisis de la zona euro es en primera instancia una crisis de deuda, que incluiría entre sus causas principales "la gran turbulencia iniciada en los mercados financieros de Estados Unidos en 2007" (Lapavitsas et ál. 2011, p. 132), vinculada a la crisis inmobiliaria. Dicha deuda se habría acumulado como consecuencia de la financiarización experimentada por los países de la periferia europea: Grecia, España y Portugal, principalmente. La financiarización, por su parte, tendría sus raíces en la incorporación de estos países en la Unión Económica y Monetaria (UEM), organizada en torno a un Banco Central Europeo independiente y dedicado prioritariamente a controlar la inflación, además de la renuncia al manejo de política monetaria y cambiaria que tal incorporación (i.e., la moneda única) implicaba. Como resultado de una política rígida y duradera de estancamiento de los salarios en Alemania, el país más competitivo de la Unión Europea, los países periféricos habrían experimentado una pérdida significativa de competitividad, traducida en un deterioro sistemático de sus cuentas corrientes y "de forma complementaria en un superávit igualmente sistemático para Alemania" (Lapavitsas et ál. 2011, p. 132). Esto es lo que Lapavitsas Ilama la política de "empobrecimiento del vecino", planteamiento interesante en tanto muestra con claridad lo que la "apoteosis" de la edificación de la Unión Europea y del euro escondía: contribuir en el proceso de acumulación y valorización del capital, cuyas agudas contradicciones inexorables lo condenan a crisis periódicas y necesarias, cada vez más profundas y peligrosas. $Y$ particularmente, la recuperación de la tasa de ganancia que, como ya se mencionó, había sufrido una caída durante los años 70.

Tal proyecto estaba destinado a beneficiar primariamente a un grupo específico de capitalistas: los de los países del centro de la región, revelando con esto la existencia de dos conflictos entrelazados: el conflicto centro-periferia y el conflicto fundamental entre capital y trabajo. Y es que la política de "empobrecimiento del vecino" estaba basada en la clásica política capitalista de "empobrecimiento de la clase trabajadora", de su pauperización relativa. De acuerdo a Del Rosal y Murillo (2012), el euro en realidad no sería más que un instrumento de disciplinamiento de la clase trabajadora, en tanto el eje central constitutivo de la integración monetaria habría sido el salario, variable 
"flexible" a disposición. De modo que el conflicto centro-periferia sería dirimido a través del conflicto capital-trabajo. Así, los países de la periferia, necesitando mejorar su situación como fuera posible, se habrían dedicado a tratar de compensar el desbalance en cuenta corriente con crecientes préstamos externos solicitados a los países superavitarios como Alemania, al tiempo que socavaban las remuneraciones de la clase trabajadora en su intento por recuperar la competitividad. La consecuencia no se haría esperar: un inmanejable monto de deuda pública y privada (bancos, familias, empresas, etc.) similar a la sufrida por América Latina durante la "década perdida".

La crisis de la zona euro sería pues producto de "los sesgos estructurales en el interior de la zona euro" (Lapavitsas et ál. 2011, p. 132), esto es, de tratar de aplicar medidas comunes (control de la inflación, del déficit fiscal, etc.) a países en condiciones y niveles de productividad muy disímiles, incapaces, además, de aplicar políticas monetarias y cambiarias que pudieran beneficiarles o ayudarles a compensar. Su origen último, sin embargo, habría sido el ataque sin tregua a los salarios que la clase trabajadora sufriera en Alemania y que, una vez dentro de la Unión, habría generado problemas de competitividad para los países con mayores desventajas productivas dentro de la zona, problemas que acelerarían el proceso de financiarización (endeudamiento) ya bastante esparcido por el mundo (empezando por Estados Unidos), cosa que no haría más que reflejar el fracaso histórico de la zona euro. ${ }^{16}$

Es preciso observar que el estudio de la crisis de la UEM debe ubicarse en el marco de la crisis capitalista para, desde ahí, analizar las formas propias con que las tendencias del modo de producción se expresan en esa área específica. De lo contrario, dicho estudio carecería de generalidad, y de ser una crisis sistémica del capital, pasaría a considerarse como algo accidental, peculiar a la región, a sus políticas coyunturales, o bien a la "injusta" o "inapropiada" distribución del ingreso. Desde este punto de vista es que debe valorarse la postura de la SOAS, que brinda aportes importantes en tanto expone los factores de profundización de la crisis en la UE, la forma en que se desarrolla, el conflicto centro-periferia producto del proceso de integración particular, etc.

En general, y de acuerdo a Mateo Tomé (2011, sin número de página. Traducido del inglés), la tesis de la financiarización adolece de los siguientes vacíos:

En primer lugar, la atribución de la responsabilidad de la crisis a una excesiva expansión del sector financiero se 
asemeja a las teorías de la desproporción que emergieron después de la publicación del libro II de El Capital... En segundo lugar, y con referencia al excedente y a la inversión, algunos autores culpan a la financiarización de la caída en la demanda de consumo e inversión (una brecha de demanda), y especificamente, culpabilizan a la política neoliberal. Mientras que otros, relacionados a la escuela del MR, consideran esta situación como característica del capitalismo contemporáneo, para concluir que la financiarización es una consecuencia de otras desproporciones entre producción y demanda... En todo caso, las dos visiones son consistentes con la tradición de la insuficiencia en el consumo, presente en diferentes escuelas de pensamiento económico. ${ }^{17}$ $Y$ en tercer lugar, la financiarización podría haber causado un excesiva absorción de excedente en la forma de intereses y dividendos que habrían reducido la tasa neta de beneficios, i.e., resultando en una crisis debido a la constricción de los beneficios llas teorías del profit squeeze, de espíritu más ricardiano que marxista]. De forma similar, esta aproximación puede ser ubicada metodológicamente en un conjunto más amplio de teorías que explican la crisis a través de una expansión de actividades improductivas, el estrujamiento de los beneficios y los [elevados] impuestos del Estado, tratando de localizar la fuente del problema en la distribución del excedente, y en sus efectos negativos sobre la inversión. En resumen, vemos que esta tesis de la financiarización no considera una tendencia inherente del sistema capitalista hacia la crisis... la crisis no sería un elemento necesario e inevitable del proceso de acumulación, sino que podría ser evitada con un correcta gestión que restablezca las condiciones de proporcionalidad entre los sectores y segmentos del capital, así como mediante una política de redistribución que resuelva los desbalances entre oferta y demanda ["armonicismo"].

Estas serían las implicaciones políticas de teorías incapaces de develar la esencia del modo de producción capitalista. Pudiendo ser perfectible a través de política económica y mecanismos de similar ín- dole, y siendo las crisis fenómenos ajenos a la propia naturaleza del sistema, cualquier intento de transformación revolucionaria quedaría desvirtuado por inútil. Estaríamos ante un análisis por completo ahis- 
tórico de la crisis y de la sociedad capitalista, sin ninguna relación con la teoría laboral del valor (TLV), imprescindible si lo que se quiere es comprender el funcionamiento de este modo de producción.

\section{La Ley de la Tendencia Decreciente de la Tasa de Ganancia (LTDTG)}

Pero, junto a estos autores, existen otros que, partiendo de las leyes que rigen el funcionamiento del modo de producción capitalista, y en específico de la ley de la LTDTG, es decir, considerando el carácter social e histórico del capitalismo, analizan la crisis como parte orgánica del proceso de acumulación del capital, de sus límites y contradicciones. Estos autores consideran la crisis actual como una crisis "normal" del modo de producción capitalista (cuyo origen se ubica en la esfera productiva, específicamente en la forma y lógica de acumulación), esperable, inevitable, natural dado su contradictorio funcionamiento, e incluso necesaria para su continua reproducción. Colocan así los movimientos financie- ros como una consecuencia de la crisis, una forma de manifestarse, $\mathrm{O}$, en todo caso, uno de sus elementos detonantes.

Shaikh (2010), por ejemplo, para quien el capitalismo necesita modificar constantemente su coraza con el fin de preservar intacto su núcleo (lo que puede dar lugar a teorías e interpretaciones confusas como las presentadas arriba), sostiene que este régimen de producción (refiriéndose al estadounidense principalmente), tras recuperar la tasa de ganancia luego de la crisis de los años 70, enfrenta hoy un colapso generado por una caída violenta de las tasas de interés. En sus palabras:

[L]a tasa general de ganancia fue sacada de su larga depresión a través de un ataque concertado al trabajo, ${ }^{18}$ que causó que los salarios reales después de 1982 [en Estados Unidos] crecieran mucho más lentamente que en el pasado... la tasa de interés cayó rápidamente después de 1982... el efecto neto de estos dos movimientos, sin precedentes en la historia, fue el incremento enorme de la tasa de beneficio empresarial. Este es el secreto del gran auge que comenzó en los años 80. Pero fue inherentemente contradictorio. La caída dramática en la tasa de interés desató una ola de endeudamiento, y las cargas por deuda de los diferentes sectores crecieron de manera espectacular. Los hogares, cuyo ingreso real había sido comprimido por la desaceleración en el crecimiento 
del salario real, recibieron ofertas de deuda cada vez más baratas con el fin de mantener el crecimiento en el gasto de consumo. En consecuencia... las tasas de deuda-ingreso de los hogares crecieron dramáticamente en los años $80 \ldots$ una vez que la tasa de interés ha sido reducida a cero (es de 0.0017 , i.e. 0.17 por ciento en este preciso momento), no hay más lugar adonde ir en este aspecto. (Shaikh 2010, pp. 52-54. Traducido del Inglés. Énfasis del autor.)

La crisis actual sería resultado del agotamiento del mecanismo implementado para recuperar la tasa de ganancia durante la crisis capitalista anterior, mecanismo conformado por un incremento (artificial) de la tasa de explotación (reducción progresiva del salario real ${ }^{19}$ ) y una reducción acelerada de la tasa de interés a fin de recuperar las ganancias empresariales. ${ }^{20}$ En otras palabras, para este autor -y en un espíritu similar al de Duménil, Lévy y Husson-, la crisis actual estaría reflejando un decaimiento de las medidas implementadas para recuperar la tasa de ganancia. Sin embargo, la diferencia fundamental es que para él las leyes internas del capitalismo no admiten modificación, y si bien pueden mitigarse temporalmente sus efectos, tarde o temprano las contradicciones congénitas darán lugar a crisis que serán cada vez más profundas y con secuelas cada vez más terribles para la clase trabajadora. Vale decir, la tasa de ganancia volverá a caer y una nueva crisis se hará presente. No hay lugar para la gestión ni para el "perfeccionamiento" del capitalismo. Esta es, justamente, la explicación de la crisis actual, a saber, una crisis à la Marx, aunque con sus respectivas peculiaridades, propias de este momento histórico.

Kliman (2010), por su parte, también defensor de la LTDTG, y para quien es incorrecto e incluso peligroso tipificar la crisis actual como una crisis irreductiblemente financiera o del "neoliberalismo", plantea lo siguiente:

¿[Q]ué causó el estancamiento relativo? La explicación más obvia, y por ende la explicación que es prima facie la más convincente, es ésta:

1. la tasa de beneficio cayó, y dado que no se destruyó suficiente valor-capital como para restituir la rentabilidad, la tasa de beneficio no pudo recuperarse de forma significativa después de la depresión económica de la mitad de los años 70 y principios de los 80; 
2. la persistente caída en la tasa de beneficio produjo una persistente caída en la tasa de acumulación de capital; y

3. la caída en la tasa de acumulación condujo a su vez a un crecimiento lento del PIB per capita, del producto de las corporaciones y de la compensación de los empleados, al incremento de las cargas de deuda, etc. (Kliman 2010, sin número de página. Traducido del Inglés. Énfasis del autor.)

A diferencia de Shaikh, ${ }^{21}$ pero sobre todo en abierta crítica a Duménil \& Lévy y Husson, Kliman (2010), sostiene que no hubo recuperación alguna de la tasa de ganancia luego de la depresión experimentada en la década de los 70 , y ello se debió a que no se permitió (desde los gobiernos) que se ejecutara adecuadamente la función de "limpieza" de capital débil e inepto que las crisis echan a andar (su carácter necesario).

Temerosos de una nueva "Gran Depresión" y de la radicalización de la clase trabajadora que la acompañó, los Estados habrían restringido la actuación libre de las fuerzas de mercado, rescatando empresas y evitando bancarrotas con el fin de retardar y prevenir la destrucción de capital; esto habría, en ese momento, logra- do la contención del problema, pero también su prolongación. ${ }^{22}$ La economía global nunca se habría recuperado por completo del desplome de los años 70, y todo este proceso habría llevado a la ampliación de deuda, la formación de burbujas y a la explosión de las mismas. La crisis actual, y la subsecuente desaceleración económica, estaría pues asociada a la explosión de una gigantesca burbuja en el sector inmobiliario y en la bolsa de valores como consecuencia del relativo estancamiento económico, siendo la continua caída en la tasa de ganancia el elemento explicativo crucial. De este modo, afirma Kliman (2010), es por completo erróneo suponer que la tasa de acumulación de capital no refleja la evolución en la tasa de ganancia, como Duménil \& Lévy y Husson plantean:

Si bien es cierto que, al examinar el período desde la década de los 80, como Husson lo hace en una crítica reciente a mi trabajo empírico sobre la tasa de ganancia, se encuentra una brecha creciente entre la tasa de beneficio y la de acumulación... esto es sólo porque la brecha que existía en ese momento era anormal e insosteniblemente pequeña, 
y ello no tiene ninguna relación con ningún 'régimen de acumulación' neoliberal distintivo y sin precedentes. Lo que paso fue esto: La tasa de ganancia cayó violentamente a principios de los 80, mientras que el decline en la tasa de acumulación era al principio más lento y modesto. Como consecuencia, la inversión neta como porcentaje de las ganancias después-de-impuestos se disparó a un promedio de $117 \%$ entre 1980 y 1986. Así, jlas corporaciones estadounidenses estaban invirtiendo $17 \%$ más de las ganancias después-de-impuestos que en realidad tenían! Claramente, tal situación no podía persistir. De forma que la brecha entre las tasas de ganancia y acumulación que había existido anteriormente fue recuperada gradualmente. Pero, por lo menos a lo largo de 2001, no hubo ningún ensanchamiento de larga duración de la brecha (Kliman 2010, sin número de página. Traducido del Inglés.)

En efecto, de acuerdo a Marx (1968), la acumulación está directamente determinada por la tasa de ganancia, y aún más por el monto total de ganancias. En otras palabras, en el capitalismo, la tasa de acumulación refleja, en general, el comportamiento de la tasa de ganancia.

Por otra parte, lo que está detrás de las diferentes percepciones en torno la recuperación de la tasa de ganancia es el debate sobre cómo medir el capital constante. ${ }^{23}$ Mientras que los que afirman que dicha tasa se recuperó después de los años 70 (i.e., Duménil \& Lévy y Husson, principalmente) lo hacen con los costos actuales o costos de reemplazo, Kliman asevera que debe hacerse con los costos históricos (los costos que fueron efectivamente pagados por la empresa en el momento de la inversión). De acuerdo con este autor (Kliman
2010), es la tasa calculada de esta manera lo que las empresas y los inversores utilizan en realidad para tomar sus decisiones y es, adicionalmente, lo que buscan maximizar. De emplearse los costos de reemplazo, no sólo las estadísticas presentarían una "falsa" evolución de la tasa de beneficio, sino que, adicionalmente, no presentarían tasa de beneficio alguna, al no poder considerarse, dicho ratio, como una tasa de ganancia en el sentido normal del término. Como es lógico, dicha tasa carecería, además, de una relación clara con la tasa de acumulación de capital, siendo imposible derivar con ella conclusiones certeras acerca del comportamiento y la relación de ambas variables. Adicionalmente, Duménil y Husson (Ver Kliman 2010) argumentan que la tasa de ganancia calculada con los costos corrientes permite corregir los efectos de la 
inflación, mientras que Kliman afirma que ésta no es una corrección adecuada, ya que, al ser costos de reemplazo, éstos no consideran los cambios en la composición del capital (maquinaria, etc.):

[P]ara ajustar adecuadamente las tasas de ganancia, de modo que no contengan los efectos de la inflación, uno debe de controlar los cambios en el nivel general de precios y no computar la 'tasa de ganancia' a precios corrientes. Mis estimaciones de tasas de beneficio corrigiendo la inflación indican que el movimiento de dichas tasas desde el inicio de los años 80 no discrepó de forma sustancial de los movimientos de las tasas de beneficio a costos-históricos no corregidas (Kliman 2010, sin número de pagina. Traducido del Inglés).

Es interesante observar que si bien Duménil y Lévy tienen razón, Kliman también la tiene; dependerá del punto de vista del que se realice el análisis, si desde el punto de vista de la creación de valor o desde el punto de vista del empresario capitalista. El valor de las mercancías, en forma rigurosa, y tal como lo plantea Marx en no pocos pasajes, ${ }^{24}$ cambia de un período a otro, ya sea por variaciones en la productividad del trabajo, o en la intensidad y duración del mismo. En este sentido, el valor de los componentes del capital constante utilizado, vale decir, el capital constante consumido durante un período productivo, habrán variado al final del mismo, por lo que su cálculo tendría que incorporar dichas modificaciones. Así, tomando en cuenta lo anterior, la tasa de beneficio tendría que calcularse utilizando los costos de reemplazo o costos corrientes, reflejándose en ella el "verdadero" valor de sus partes constitutivas. Por otra parte, y como también lo señala Marx en no pocas ocasiones, los capitalistas desconocen la división entre capital constante y capital variable; esto es, para sus cálculos y proyecciones de rentabilidad, tal división no es tomada en cuenta; de hecho se trata de una división que ignoran por completo. Para ellos, la ganancia surge de todo su capital, y ésta será mayor en tanto mayor sea el tamaño de dicho capital. De modo que para sus cálculos, la comparación del valor de las mismas mercancías al inicio de un período y en un período posterior no tiene mayor importancia. Recuérdese que el precio de costo, que Marx define en el Capítulo I del Tomo III de El Capital, está referido al desembolso que el capitalista realiza, y que él percibe como costo de producción para la elaboración de las mercancías. Desde esta perspectiva, Kliman tendría razón, en tanto para calcular sus beneficios los capitalistas tomarán en cuenta lo que han pagado, vale 
decir, lo que a ellos les ha costado producir esas mercancías. Y en este caso, la tasa de ganancia tendría que calcularse a costos históricos, es decir, de acuerdo al desembolso que efectivamente habrían realizado, y no de acuerdo al valor de sus componentes.

En realidad, Duménil y Lévy, aunque admitan cambios en los precios de las partes constitutivas de la tasa de ganancia a lo largo de un período productivo, lo que toman en cuenta para sus cálculos son los precios de mercado corrientes que, a largo plazo y para toda la economía, coinciden con los precios de producción.

Dado que los defensores de la "tasa de beneficio" a costoscorrientes, como Kliman (2010) les Ilama, fallan en observar el numeral (1) de la explicación obvia y plausible -esto es, que la tasa de beneficio continuó cayendo-, no pueden tampoco aceptar el punto (2), lo que los deja en un serio problema: explicar, de alguna manera, "el extremadamente curioso hecho que nada más -tasa de acumulación, crecimiento del $\mathrm{PIB}$, producto de las corporaciones, compensación de los empleados, etc.- se recuperó en respuesta a la recuperación de la 'tasa de ganancia."' (Kliman 2010, sin número de página. Traducido del Inglés) $Y$ es aquí cuando deben de echar mano del "régimen de acumulación neoliberal", surgido al inicio de los años 80 , y responsable de que la tasa de acumulación cayera no por falta de beneficios, sino porque fueran desviadas hacia los mercados financieros. De ahí que consideren que la actual crisis capitalista sea una crisis financiera en lugar de una crisis basada en problemas de rentabilidad subyacentes.

El Esquema 1, presentado a continuación, intenta ilustrar y resumir todo lo antes expuesto. 


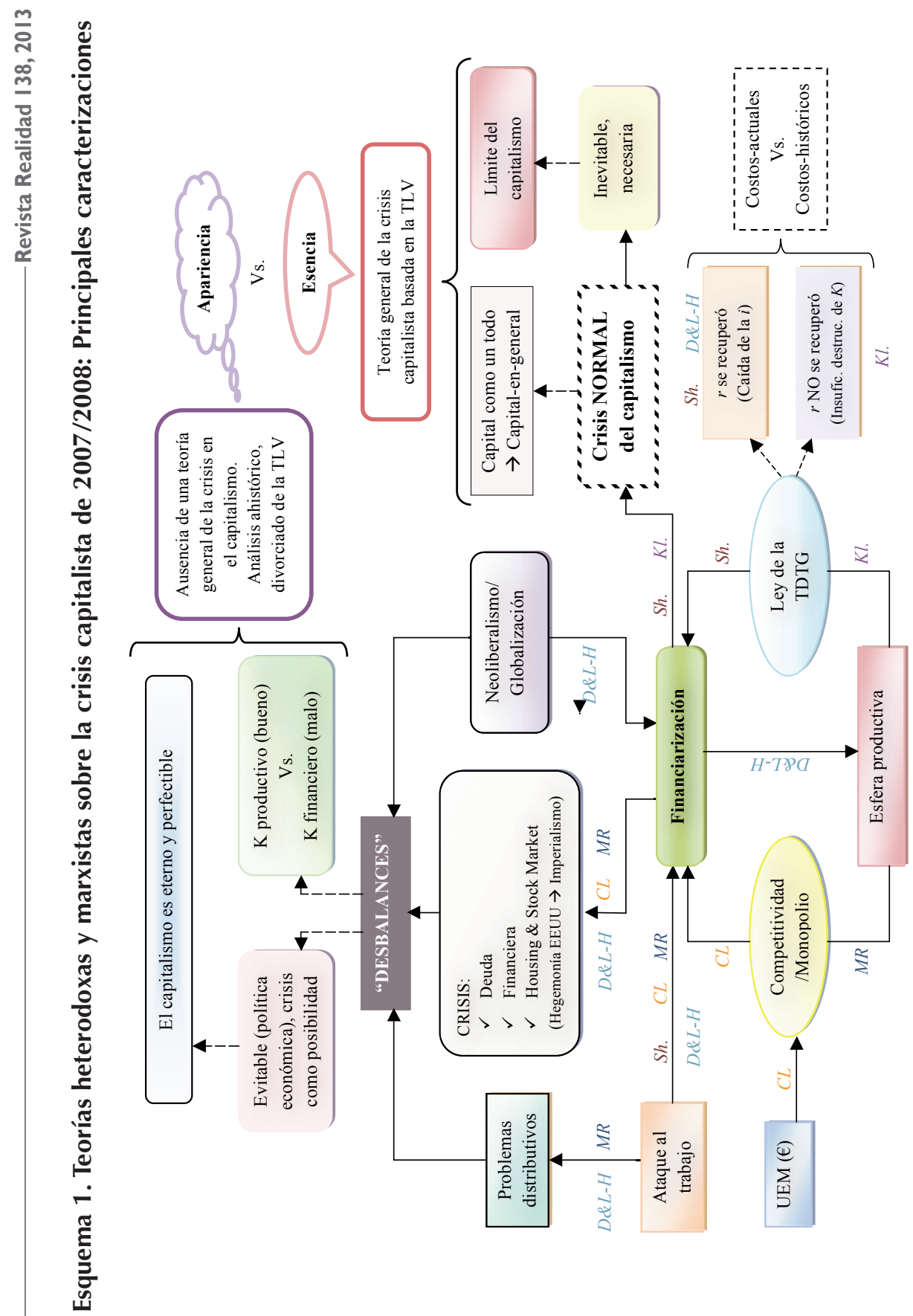


Nota: Las letras ubicadas sobre las flechas en la parte inferior del esquema indican las iniciales de los que son, tal vez, los autores más representativos de las distintas teorías consideradas. Así:

$M R=$ La escuela del Monthly Review, que incluye autores como Paul Sweezy, Fred Magdoff, John Bellamy Foster, entre otros;

$C L=$ Costas Lapavitsas (del SOAS - School of Oriental and Afrincan Studies de la Universidad de Londres);

$D \& L-H=($ Gérard) Duménil \& (Domenique) Lévy - (Michel) Husson

$K l .=($ Andrew $)$ Kliman

Sh. $=($ Anwar $)$ Shaikh

El sentido de las flechas indica causalidad. Las flechas discontinuas en la parte superior indican "implicación" como lo entiende la lógica proposicional.

\section{Observaciones finales}

Es necesario remarcar que las implicaciones políticas de esta controversia son profundas. Si aceptamos que las causas de la crisis son las medidas neoliberales y la financiarización, esto es, que se trata de una "crisis del neoliberalismo" y no de una crisis del capitalismo, significa que todo lo que necesitamos para prevenir este tipo de crisis, y para "resolver" la actual, es suprimir el neoliberalismo junto con el "capitalismo financiarizado". Un cambio de modo de producción no sería por tanto necesario. Sin embargo, si la crisis es una crisis del capitalismo en la que las contradicciones y antagonismos de la producción burguesa quedan violentamente reveladas (Marx 1968), lo que tenemos que hacer para prevenirla y eliminarla es echar por tierra este modo de producción cuyo carácter contradictorio no puede ser borrado a través de una simple negación. ${ }^{25}$ La reforma de la estructura del sistema financiero mundial, las políticas monetarias y fiscales, la nacionalización de bienes, etc., podrían, en el mejor de los casos, posponer la siguiente crisis, mas nunca evitarla.

Así, las teorías enraizadas en las leyes propias del modo de producción capitalista que consideran su dimensión social e histórica, no sólo dan cuenta de la existencia de una teoría general de las crisis específica para dicho modo de producción, sino que además son capaces de dejar al descubierto la esencia del mismo. Lo contrario se observa en las teorías que explican simples expresiones fenoménicas de la crisis actual. De hecho, como lo señala Marx (1968), explicar las crisis en base a sus meras manifestaciones es pretender explicar la crisis por medio de la crisis. Las crisis sólo pueden explicarse a partir de las condiciones generales de la 
producción capitalista a partir del movimiento real de este modo de producción, donde la competencia y el crédito (dinero como medio de pago) juegan un papel fundamental.

O como lo plantea Mateo Tomé:

[E]xiste en estas explicaciones sobre la financiarización la ausencia de un análisis que diferencie las economías capitalistas en abstracto, en el sentido de modo de producción históricamente determinado, de las formaciones económicas particulares que moldean sus partes constitutivas. Este aspecto es importante desde la perspectiva de la dicotomía entre las causas (profundas o esenciales) y las consecuencias (superficiales o visibles)... Por ejemplo, desde la perspectiva de una economía dada, uno puede ciertamente hablar de financiarización siempre y cuando dicha economía muestre un grado elevado de dependencia de los mercados financieros y que esto determine el tipo de política económica que es implementada... es posible considerar, en estos términos, la crisis... desde la perspectiva financiera, pero pudiera también ocurrir desde una perspectiva comercial... [Todos estos son] incidentes que, desde una visión limitada, confirman la existencia de la financiarización, y suponen explicaciones parciales de la crisis que, en última instancia, no se relacionan con el sistema económico capitalista como modo de producción abstracto... [Tales caracterizaciones] estarían limitadas a describir las manifestaciones del fenómeno, sin preguntarse por sus cimientos esenciales. (2011. Sin número de página. Traducido del Inglés)

Como dijéramos en un inicio, las caracterizaciones superficiales de la crisis capitalista no son teorías inocentes, por mucho que sus autores se autoproclamen "apóstoles" de Marx. El peligro de este tipo de interpretaciones radica en el nada menor error de no identificar correctamente al enemigo, cosa que nos lleva a clamar en contra del "capitalismo salvaje", del "sistema financiero sin control" y de los "especuladores sin corazón". ${ }^{26}$ Parecería pues que un manejo más responsable y apropiado de la política económica, que contemple las restricciones necesarias para los corto-placistas y avariciosos deseos de los jugadores de la bolsa, nos permitiría evitar las crisis, haciendo innecesaria toda modificación estructural adicional, como si el Estado fuera, en efecto, un "árbitro parcial" preocupado por "el bienestar general", y no lo que en realidad es: un instrumento de legitimación y de dominación al servicio del capital. La incapacidad de com- 
prender a cabalidad el régimen de producción actual, se traduce en incapacidad de luchar contra él. De ahí que toda teoría que pretenda, deliberadamente o no, enmascarar y mitificar la verdadera naturaleza del sistema capitalista, debe ser rechazada y puesta en evidencia.

\section{Referencias}

os Del Rosal, Mario y Murillo, Javier (2012) "El Euro como mecanismo de aplicación del ajuste salarial", ponencia presentada en las Jornadas de Economía Critica, Sevilla. Disponible en: http://www.ucm.es/info/ec/ jec13/index.htm

ç Duménil, Gérard y Lévy, Dominique (2004) Capital Resurgent. Roots of the Neoliberal Revolution, London-Massachusetts: Harvard University Press.

os Duménil, Gérard y Lévy, Dominique (2009a) "Thirty years of Neoliberalism under U.S. Hegemony". Disponible en: http://www.jourdan.ens. fr/levy/biblioa.htm

os Duménil, Gérard y Lévy, Dominique (2009b) "The Crisis of Neoliberalism and U.S. Hegemony". Disponible en: http://www.jourdan.ens.fr/ levy/biblioa.htm

os Duménil, Gérard y Lévy, Dominique (2011) "The Crisis of the Early $21^{\text {st }}$ Century: A Critical Review of Alternative Interpretations" (Preliminar draft). Disponible en: http://www.jourdan.ens.fr/levy/dle2011e.pdf

os Gill, Louis (2002) Fundamentos y límites del capitalismo, Madrid: Editorial Trotta.

os Husson, Michel (2008a) "The Upward Trend in the Rate of Exploitation", International Viewpont, No. 397. Disponible en: http://internationalviewpoint.org/spip.php?article1421

os Husson, Michel (2008b) "A Systemic Crisis. Both Global and LongLasting", Workers' Liberty. Disponible en: http://www.workersliberty. org/story/2008/07/21/marxists-capitalist-crisis-7-michel-husson-systemiccrisis-both-global-and-long-las

os Husson, Michel (2008c) "Toxic Capitalism", International Viewpoint, No. 406. Disponible en: http://internationalviewpoint.org/spip. php?article1551

os Husson Michel (2009a) "The Crisis of Neo-Liberal Capitalism", Workers' Liberty. Disponible en: http://www.workersliberty.org/story/2009/01/04/ marxist-economists-comment-again-crisis-1-michel-husson-crisis-neoliberal-capitali 
os Husson, Michel (2009b) "Financial Crisis or Crisis of Capitalism?" (mimeo). Disponible en: http://hussonet.free.fr/denkeng9.pdf

os Husson, Michel (2010) "The debate on the rate of profit", en International Viewpoint No. 426.

os Katz, Claudio (2010) "Interpretaciones de la crisis", documento de trabajo. Disponible en: http://www.lahaine.org/b2-img10/katz_interpr.pdf

os Kliman, Andrew (2010) "Appearance and Essence: Neoliberalism, Financialization, and the Underlying Crisis of Capitalist Production". Disponible en: http://www.marxisthumanistinitiative.org/economiccrisis/appearance-and-essence-neoliberalism-financialization-and-theunderlying-crisis-of-capitalist-production.html

os Lapavitsas, Costas, et ál. (2011) "Crisis en la Zona Euro: Perspectiva de un impago en la periferia y la salida de la moneda única común", en Revista de Economía Crítica, No. 11, pp. 131-171.

os Marx, Karl (1973) [1857-58] Grundrisse: Foundations of the Critique of Political Economy, London: Penguin.

os Marx, Karl (1995) [1894] El Capital, Tomo III, México, D.F.: Fondo de Cultura Económica.

os Marx, Karl (1968) [1863] Theories of the Surplus Value, Progress Publishers: Moscow.

os Mateo Tomé, Juan Pablo (2011) "The financialization as a theory of crisis in a historical perspective: nothing new under the sun", Working Paper Series, No. 262, Political Economy Research Institute. Disponible en: http://www.peri.umass.edu/fileadmin/pdf/working_papers/working_papers_251-300/WP262.pdf

os Palley, Th., Keen, S., Kliman, A., Shaikh, A., Roberts, M., Mosley, F., et ál. (2012) "Radical Economic Theories of the Current Economic Crisis", documento preparado para la URPE-Occupy Summer Conference. Disponible en: http://thenextrecession.files.wordpress.com/2012/07/ crisissummaries.pdf

os Shaikh, Anwar (2010) "The First Great Depression of the $21^{\text {st }}$ Century", en Panitch, L., et ál. (2010) Socialist Register 2011: The crisis this time, The Merlin Press: Londres, pp. 44-63.

os Tapia, José (2009) "Causas de la crisis: especulación financiera, burbujas inmobiliarias, machismo desaforado y otras explicaciones económicas de nuestra penuria", en Ensayos de Economía, No. 34, pp. 35-46. 
os Weeks, John (2011) "The Euro Crisis in 7 Simple Charts", The Real News. Disponible en: http://therealnews.com/t2/component/content/ article/81-more-blog-posts-from-john-weeks/866-the-euro-crisis-in7-simple-charts-theyre-telling-you-a-real-pack-of-lies

Notas

1 "[E]stas disidencias conceptuales no tienen correlatos políticos directos. De una misma interpretación de los desequilibrios económicos se pueden extraer conclusiones políticas divergentes y también es factible el proceso inverso... Ninguna teoría socialista de la crisis conduce de por sí a la moderación reformista o a la radicalidad revolucionaria.” (Katz 2010, p. 13.)

2 Ver Duménil y Lévy 2011 y Husson 2009a.

3 Todo lo que ahora, con Europa en crisis, se les aplica a los países miembros, especialmente a los del sur -los así llamados "PIGS" -, bajo el nombre de "Medidas de Austeridad" y con el patrocinio de la Unión Europea.

4 "A finales del siglo diecinueve, las finanzas crearon su propio universo institucional, acompañando el desarrollo de grandes sociedades anónimas y la revolución gerencial -sociedades de inversión y redes de compañías financieras, el rol central del mercado de valores, un sistema crediticio volcado hacia los accionistas, etc. Las finanzas rigieron pues de acuerdo a su criterio e intereses... Iniciando en 1933, el New Deal provocó la intervención masiva del estado en mecanismos financieros y macroeconómicos. Tal intervención se extendió hasta fijar una estructura legislativa y regulatoria que limitó de forma significativa el poder de las finanzas y constituyó una de las principales características del período de post-

Segunda Guerra Mundial.” (Duménil y Lévy 2004, pp.156-159. Traducido del Inglés) De acuerdo a estos autores, fue la disolución unilateral (léase, Estados Unidos) de Bretton Woods y el inicio del neoliberalismo lo que permitió a las finanzas tomar de nuevo el control de la creación monetaria e imponer una política y un curso de eventos similar al observado antes de la Gran Depresión de 1929. "Las finanzas se concedieron una libertad de acción extremadamente peligrosa, que hace recordar directamente algunos aspectos de las décadas anteriores a la Gran Depresión. Esta libertad permitió una inestabilidad tremenda a nivel nacional y especialmente internacional: un incremento dramático de las actividades financieras, la fluctuación impredecible de las monedas, y excesivos movimientos de capitales. El capitalismo revivió algunas de sus anteriores aberraciones, que se creían superadas en los años 60 -las crisis financieras nacionales e internacionales y la locura de la bolsa de valores." (Duménil y Lévy 2004, p. 167. Traducido del Inglés.)

5 "Sin simplificar demasiado, puede afirmarse que las finanzas se financian a sí mismas, pero no financian la inversión." (Duménil y Lévy 2004, p. 124. Traducido del Inglés.)

6 "La cuestión del incremento de la deuda y la subsecuente proliferación financiera es analizada desde la perspectiva de la necesidad de cerrar la brecha de demanda, lo que puede ser generalizado 
y conduce a la tradición de la teoría del consumo insuficiente." (Mateo Tomé 2011, sin número de página. Traducido del Inglés)

7 Recuérdese que, de acuerdo a esta teoría, es de la plusvalía exprimida a los trabajadores en la esfera productiva de donde surgen los intereses que el capital financiero reclama como su parte en el "botín", esto es, como beneficio. Ver Marx (1995), especialmente los Capítulos XXI - XXIII.

8 "Los pos-keynesianos han retomado viejos cuestionamientos morales a la actividad improductiva. Denuncian el descaro de Wall Street, la estafa de los ahorristas y el chantaje de las agencias calificadoras contra los países endeudados. Pero olvidan que la especulación es una actividad constitutiva y no opcional al capitalismo. Los bancos no forman un mundo aparte. Operan como complemento de la inversión y lucran desenvolviendo una actividad requerida por sus pares del comercio y la producción. El capitalismo enteramente productivo que imagina la heterodoxia nunca existió. Al observar la tiranía de los financistas como un mal divorciado de la acumulación, se olvida también el lugar estratégico que han ocupado los banqueros en la reorganización general del capitalismo neoliberal. Esa gravitación contribuyó a imponer el incremento general de la tasa de explotación que reclamó toda la clase dominante. Mediante su control del crédito, los banqueros definen actualmente el curso del ajuste que demandan todos los capitalistas y comandan las drásticas cirugías sociales que requiere el sistema para reproducirse. Lejos de introducir una distorsión en el capitalismo contemporáneo han actuado en función de las necesidades de este modo de producción.” (Katz 2010, pp. 4-5)
9 Ver también Duménil y Lévy 2009a y Duménil y Lévy 2009b.

10 Ver por ejemplo Husson 2008a, 2008b, 2008c, 2009b y 2010.

11 Nótese aquí lo mencionado sobre la atención prestada a la "desarmonía" o "desbalances" entre oferta y demanda, que sugiere cierta tendencia hacia las teorías del consumo insuficiente, de tradición keynesiana.

12 Como por ejemplo, necesitado de compensar la deficiente demanda de los trabajadores. Ver nota anterior.

13 Aunque, como se verá más adelante, la forma en que se calculan de estas categorías también está en debate.

14 Como señala Marx (1968), las crisis constituyen una forma de llevar a cabo la "igualación" en este complicado proceso de distribución del trabajo social a partir de la distribución del capital social entre las distintas esferas de la actividad económica.

15 Es difícil no recordar, con esta aproximación teórica, los ataques que, en un pasado no muy lejano, sufriera el "modelo keynesiano" de manos de los defensores y propulsores del neoliberalismo. Ahora, los tiros se dirigen contra este último, fallando, de nuevo (no siempre sin intención), en reconocer al verdadero enemigo: el capitalismo.

16 Esta explicación está en obvia contraposición a los argumentos, bastante comunes por cierto en tanto bastante bien publicitados por funcionales, que culpabilizan a las características "culturales" e "idiosincráticas" de los países del sur de Europa por la crisis: "Para expresar la narrativa de la corriente dominante de forma sucinta, en el sur de Europa especialmente, las personas cobran salarios demasiado altos, trabajan muy poco, reciben beneficios públicos 
excesivos y se jubilan demasiado pronto" (Weeks 2011, sin número de página. Traducido del Inglés)

17 "Los economistas heterodoxos presentan estos desequilibrios como perturbaciones de la demanda, que podrían superarse mediante las ampliaciones del consumo. Olvidan que el capitalismo no tiene remedios sustanciales para los problemas que genera con el poder adquisitivo. En su propio desarrollo incentiva objetivos contrapuestos, al propiciar la ampliación de ventas y la obtención de ganancias con menores costos salariales. Ambas metas son incompatibles, ya que la búsqueda de beneficios con bajos sueldos deteriora la posibilidad de ensanchar los mercados. En última instancia, esta contradicción -que irrumpe periódicamentederiva del divorcio existente entre las condiciones de valorización (tasa de explotación) y realización (volumen de ventas) del capital. Al desconocer esta tensión, los heterodoxos suponen que se puede evitar el ajuste neoliberal con mayor demanda y crecimiento. Pero estas propuestas son archivadas a la hora de gobernar" (Katz 2010, pp. 5-6). Estos economistas también olvidan que lejos de ser las necesidades de la reproducción social de la vida, i.e., el consumo, el fin y la lógica del capital es la ganancia. La producción de mercancías no es más que un simple medio, un mal necesario, para alcanzar eso que tanto buscan y sin lo cual no pueden (literalmente) existir.

18 Obsérvese que este argumento es un punto de encuentro con los enfoques presentados anteriormente.

19 Se trata de un incremento "artificial" de la tasa de plusvalía en tanto no se consigue ni mediante una mayor productividad del trabajo, esto es, mediante un aumento en el grado de mecaniza- ción del proceso productivo (i.e., en la composición orgánica del capital), ni mediante una prolongación en la duración del trabajo, sino más bien a través de imponer una reducción general de los salarios reales.

20 Naturalmente, no todos los autores aceptan esta explicación de la recuperación post-crisis de los años 70 . Gill (2002), por ejemplo, hace la siguiente interesante observación: "Evidentemente, un descenso de la tasa de [interés] puede tener como efecto el de estimular la inversión al reducir los costes de los prestamos, pero esto no permite de ninguna manera obtener una generalización respecto a la incidencia del nivel del tipo de interés sobre el ritmo de la actividad económica. Las decisiones de inversión dependen ante todo del nivel de la tasa de ganancia y cuando se prevé que esta será elevada, un tipo de interés elevado no supone un obstáculo para la formación de capital, en tanto siga siendo inferior a la tasa de ganancia esperada. La ilustración clásica de esta realidad es la experiencia de la depresión de los años treinta, a lo largo de la cual los reducidos tipos de interés se revelaron impotentes para estimular la reactivación.” (Gill 2002, p. 443)

21 Es necesario mencionar que, además de la observación de la LTDTG, Kliman tiene un punto en común adicional con las explicaciones de Shaikh, la caída de las tasas de interés, aunque según este autor, ésta no fuera suficiente como para, en efecto, relanzar la tasa de ganancia empresarial: "Dado que las corporaciones pagaron menos de sus ingresos de propiedad en concepto de intereses, retuvieron una mayor porción como ganancias antes-de-impuestos. Por lo tanto, la tasa de beneficios antes-de-impuestos y capital avanzado se mantuvo más o menos constante, 
incluso cuando el ratio ingreso de propiedad/capital avanzado continuó cayendo. La relativa constancia de la tasa de beneficio antes-de-impuestos desde los inicios de los años 80 es pues no un indicador de que el 'neoliberalismo' exitosamente detuviera la caída en la plusvalía por dólar de capital avanzado... Las corporaciones fueron simplemente capaces de quedarse con una porción más grande de un relativamente decreciente cúmulo de plusvalía gracias a que la parte que debían entregar a los acreedores disminuyó." (Kliman 2010, sin número de página. Traducido del Inglés.)

22 Nótese que, en una forma similar a lo sostenido por Shaikh (2010) en lo referido a la reducción de las tasas de interés, Kliman (2010) considera que hubo participación de la política económica en el desencadenamiento de la crisis actual.

$23 \mathrm{Y}$, en general, sobre cómo medir las distintas categorías. Ver al respecto Duménil y Lévy (2011), quienes critican en particular la "tasa de ganancia empresarial" enunciada por Shaikh (2010) en base al Tomo III de El Capital (Cap. XXIII).

24 Por ejemplo: "Con el crecimiento de la proporción entre capital constante y capital variable, crece también la productividad del trabajo... con la que el trabajo social opera. No obstante, como resultado de esta productividad del trabajo incrementada, una parte del capital constante existente es continuamente depreciado en valor, dado que su valor depende no del tiempo de trabajo que costó originalmente, sino del tiempo de trabajo con el que puede ser reproducido, y este es continuamente disminuido a medida que crece la productividad." (Marx 1968, p. 660. Traducido del Inglés)

25 "Las frases apologéticas utilizadas para negar las crisis son importantes en tanto siempre demuestran lo contrario de lo que quieren demostrar. Para negar las crisis, ellas afirman la unidad donde hay conflicto y contradicción. Son pues importantes en la medida en que uno puede probar que no habrán crisis si las contradicciones que ellas han borrado en su imaginación, no existieran en la realidad. Pero en realidad las crisis existen porque estas contradicciones existen. Todas las razones que presentan en contra de las crisis es una contradicción exorcizada, y, por ende, una contradicción real, que puede causar crisis. El deseo de convencerse a sí mismo de la no existencia de contradicciones es, al mismo tiempo, la expresión de un vano deseo de que las contradicciones, que están realmente presentes, no deberían existir." (Marx 1968, p. 717. Traducido del Inglés)

26 Ver Tapia 2009. 